\title{
Subjective and objective results in surgical correction of adult acquired buried penis: A single-centre observational study
}

\author{
Andrea Cocci ${ }^{1}$, Gianmartin Cito ${ }^{1}$, Marco Falcone ${ }^{2}$, Marco Capece ${ }^{3}$, Fabrizio Di Maida ${ }^{1}$, \\ Girolamo Morelli ${ }^{4}$, Nim Christopher ${ }^{5}$, David Ralph ${ }^{5}$, Giulio Garaffa ${ }^{5}$ \\ ${ }^{1}$ Careggi Hospital, Department of Urology, University of Florence, Florence, Italy; \\ ${ }^{2}$ Molinette Hospital, Department of Urology, University of Turin, Turin, Italy; \\ ${ }^{3}$ Department of Urology, University of Naples, Naples, Italy; \\ ${ }^{4}$ Department of Urology, University of Pisa, Pisa, Italy; \\ ${ }^{5}$ The Institute of Urology, UCLH, and International Andrology, London, UK.
}

\begin{abstract}
Summary Objective: The purpose of this study was to provide a detailed analysis of surgical and functional outcomes after correction of acquired buried penis in the adult.

Materials and Methods: From 2006 to 2016, we retrospectively reviewed 47 patients undergoing surgical treatment for the correction of buried penis. Functional and surgical outcomes, as well as patients' satisfaction were the main endpoints. Results: The most common complains at presentation were recurrent uro-genital infections, sexual dysfunction, voiding dysfunction and Lichen Sclerosus (LS). Surgical management steps included: circumcision (27.66\%), scrotoplasty (19.14\%), V-Y skin plasty (4.25\%), split thickness skin graft (STSG) $12.76 \%$, full thickness skin graft (FTSG) $36.17 \%$, suprapubic fat pad excision (57.44\%), abdominoplasty (25.53\%), division of the suspensory ligament (36.17\%). Postoperative complications were recorded in $15 \%$ of patients. Vaginal penetration and erectile function ended up being more effective in $97.87 \%$ (46/47) and $42.55 \%$ (20/47) of patients. Improvement in penile erogenous sensation was in $6.38 \%$ (3/47). Aesthetic appearance of genitalia fully satisfied $36.17 \%$ of patients (17/47). Overall patients' satisfaction rate resulted 76.59\% (36/47).

Conclusion: Management of adult acquired buried penis still remains a challenging task to achieve, however excellent cosmetic results can be obtained by surgical reconstruction.
\end{abstract}

KEY WORDS: Buried penis; Erectile dysfunction; Circumcision; Scrotoplasty.

Submitted 4 September 2018; Accepted 26 October 2018

\section{INTRODUCTION}

Buried penis is a congenital or acquired condition, in which the phallus is partially or totally hidden below the surface of the skin. Keyes in 1919 first stated that "absence of the penis exists when the penis, lacking its proper sheath of skin, lies buried beneath the integument of the abdomen, thigh or scrotum" (1). Concealed penis (2), webbed penis (3) and inconspicuous penis (4) are sometimes used as synonyms (5).

In most cases adult acquired buried penis is secondary to morbid obesity (6), diffuse lymphedema and skin contracture due to scarring of degenerative conditions like
Lichen Sclerosus (LS) (7); in the majority of patients more conditions coexist. The development of buried penis occurs thanks to the elasticity of penile skin and dartos, which can slide and migrate distally while the corpora remain firmly attached to the pubic branches (8). In obese patients as well as in case of diffuse lymphoedema, the pre-pubic tissue progressively envelopes the penis rendering local hygiene impossible (9). Similarly, excessive removal of penile shaft skin during circumcision, either due to surgical error or because all penile shaft skin was affected by LS, may trap the penile shaft in the pre-pubic adiposity. Moreover, diabetes mellitus, which is a relatively common finding on obese patients, may impair immunity response to local and systemic infections and therefore worsen patients' prognosis (10). Buried penis profoundly impacts patients' quality of life, as sexual and voiding function are severely compromised. In particular, during micturition, the pooling of urine and the lack of hygiene leads to skin maceration and to recurrent urinary tract infections. Moreover, the maceration of skin, which is not meant to be in contact with urine for prolonged time, may be responsible of the development of permanent degenerative changes such as LS and Carcinoma of the Penis (CP). Substantial quality of life improvement has been consistently reported after definitive surgical management (11).

The rationale of the current study was to provide a detailed analysis of surgical and functional outcomes after surgical management of acquired buried penis in the adult, in order to describe the better choice of treatment.

\section{Materials AND METHOdS}

After Institutional Review Board approval, we retrospectively identified in this single-centre observational study all patients who have undergone surgical management of acquired buried penis between January 2006 and December 2016. Demographic characteristics of patients, comorbidities, surgical procedures carried out, intra- and postoperative complications and functional outcomes after penile reconstruction were retrospectively reviewed. 
The type of surgical procedure was decided according to the extent of the suprapubic adiposity and the availability and quality of penile skin. Overall, abdominal and scrotal skin quality was determined preoperatively, while the characteristics of penile skin were assessed intraoperatively after surgical exposure of the penis. Each patient signed a written fully informed consent statement to the surgical procedure.

In case of phimosis, surgery always began with a dorsal incision of the phimotic ring, in order to guarantee adequate exposure of the penis and to assess the quality of the glans penis mucosa. A circumcising incision was then performed around the corona to free the penile shaft from the surrounding tissues. Apronectomy was carried out through a transverse abdominal incision including a lozenge of skin, in order to remove the excess of skin and adipose tissue in the prepubic region.

Following apronectomy, a suction drain was left in the cavity to reduce the risk of haematoma formation.

A thick split thickness skin graft (STSG) harvested from a relatively non-hair bearing area of the abdomen was applied on the denuded dartos to reconstruct the shaft skin. When affected by LS, the mucosa of corona and glans were reconstructed with a thin STSG (0.016 inch) harvested from the inner thigh with air dermatome, as previously described by Garaffa et al. (12).

Postoperatively, a compressive penile dressing and an indwelling urethral catheter were left in place for 1 week to optimize graft take. Patients were routinely discharged after removal of dressing and urethral catheter. From 2 weeks postoperatively, patients undergoing skin grafting were advised to introduce Phosphodiesterase Type 5inhibitors (PDE5-i) therapy, in order to encourage nocturnal erections and to promote the stretching of the graft. In this way, the scar contracture that would naturally occur during the graft healing, was minimized. Upon discharge, patients were routinely reviewed in the follow-up period at the fourth and eighth week after surgery.

Surgical outcomes were assessed at the postoperative follow-up visits using the Patient Global Impression of Improvement (PGI-I) questionnaire, in order to evaluate the functional outcomes and their satisfaction rate after surgery (13). PGI-I estimated the score that best described the postoperative condition, from 1 (very much better) to 7 (very much worse). Moreover, the International Index of Erectile Function (IIEF-5) was used to assess preoperative and postoperative sexual function (14). We used the abbreviated version, also known as IIEF-5 in the validated Italian version (15).

The scale considered the presence of the erectile dysfunction, classified as follow: severe (IIEF- $5 \leq 10$ ), moderate (IIEF-5 between 11 and 16) and mild (IIEF-5 between 17 and 25).

The Hospital Anxiety and Depression Scale (HADS) questionnaire determined the levels of anxiety and depression that a patient was experiencing pre and postoperatively, with a score from 0 to 21, categorized as follow: normal (0-7), borderline abnormal (8-10), abnormal (11-21) (16).

The differences between pre- and postoperative IIEF-15 and HADS score were compared using a paired samples Student $t$ test. All tests were two-sided with a significance set at $\mathrm{p} \leq 0.05$.

\section{RESULTS}

Overall, 47 patients were eligible in the study. The mean age at the time of surgery was $51.8 \pm 18.38$ years (range 43-69 years). Patients' demographics are reported in Table 1.

The average BMI was $30 \pm 2.32$. 16/47 (34.0\%) patients were diabetics.

The most frequent reported complaints included recurrent genital infections (8.51\%), sexual dysfunction (27.66\%), voiding dysfunction (27.66\%), LS (10.63\%) and a combination of both sexual and urinary dysfunction (25.54\%) (Figure 1).

The type of surgical approach was tailored on the individual characteristics of each patient.

Surgical procedures included circumcision (27.66\%), scrotoplasty (19.14\%), V-Y plasty of the pre-pubic region (4.25\%), skin grafting of the penile shaft (thin STSG $12.76 \%$ - thick STSG $36.17 \%$ ), suprapubic fat pad excision (57.44\%), abdominoplasty (25.53\%) and division of the suspensory ligament (36.17\%) (Figures 2-6).

The average hospital stay was $7 \pm 2$ days (range 2-14 days). No intraoperative complications were recorded.

Postoperative surgical complications occurred in 14.9\% (7/47) of cases. Complications were managed conserva-

\section{Table 1.}

Patient's characteristics $(n=47)$.

\begin{tabular}{|lc|}
\hline Parameter & Value \\
\hline Mean age, years (SD) & $51.8( \pm 18.38)$ \\
\hline Mean BMI, $\mathrm{Kg} / \mathrm{m}^{2}(\mathrm{SD})$ & $30( \pm 2.32)$ \\
\hline DM type I, $\mathrm{n}(\%)$ & $10(21.27)$ \\
\hline DM type II, $\mathrm{n}(\%)$ & $6(12.76)$ \\
\hline Hypertension, $\mathrm{n}(\%)$ & $18(38.29)$ \\
\hline Cardiovascular diseases, $\mathrm{n}(\%)$ & $8(17.0)$ \\
\hline Mean operative time, minutes (SD) & $185( \pm 91.12)$ \\
\hline Mean blood loss, ml (SD) & $180( \pm 240.2)$ \\
\hline Mean hospital stay, days (SD) & $7( \pm 6.36)$ \\
\hline Intraoperative complications, $n(\%)$ & $0(0)$ \\
\hline Postoperative complications, $n(\%)$ & $7(14.89)$ \\
\hline DM: Diabetes mellitus; BMl: Body max index; SD: Standard deviation. \\
\hline
\end{tabular}

\section{Figure 1.}

The most frequent symptoms reported by patients with clinical presentation of buried penis.

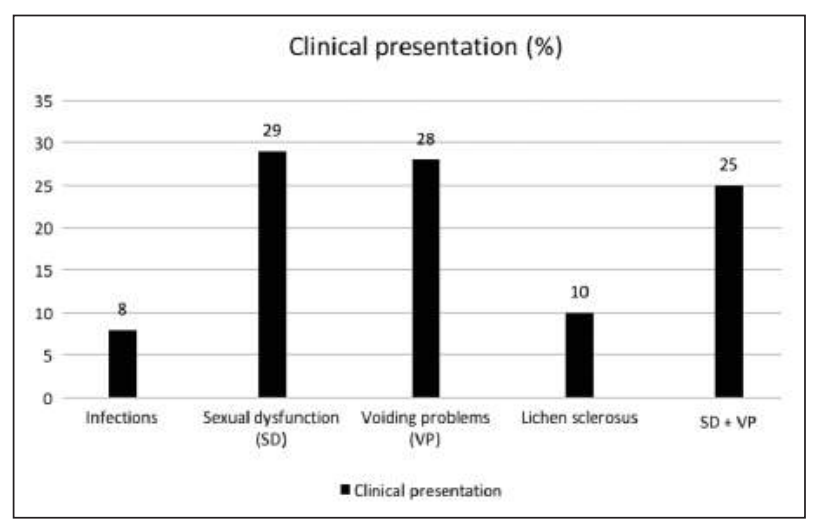


Figure 2.

One case showing the starting clinical presentation of buried penis.

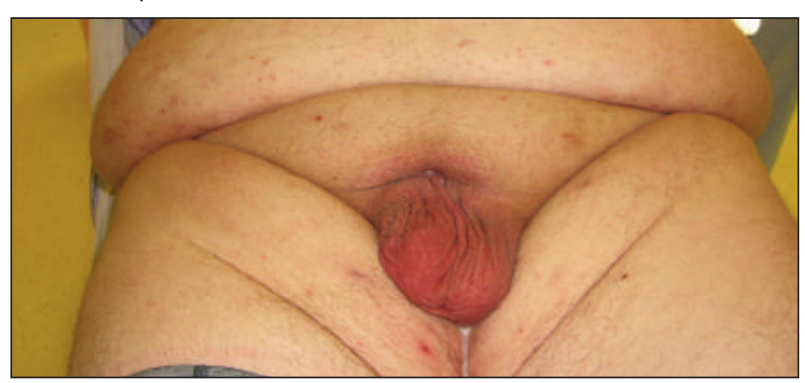

Figure 3.

One case showing the starting clinical presentation of buried penis.

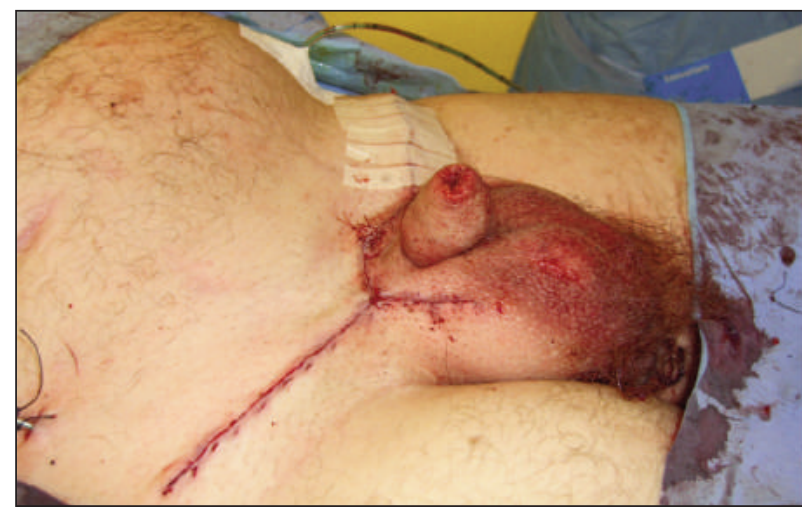

\section{Figure 4.}

Skin grafting of the penile shaft.

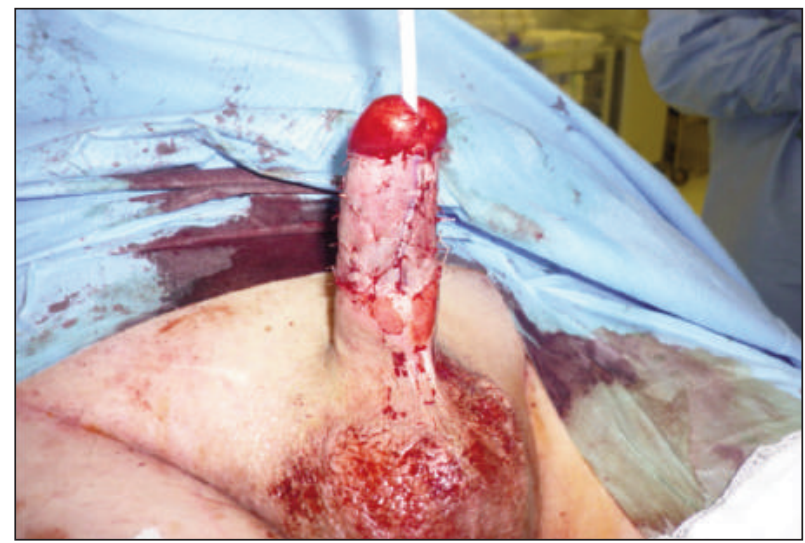

tively in 5 patients while surgical intervention was necessary in the remainder, as summarized in Table 2.

Functional results after reconstructive surgery are reported in Table 3. Comparing pre- and postoperative HADS score we found a statistically significant difference $(\mathrm{p}=0.03)$. Equally, comparing pre- and postoperative IIEF-5 score, a trend of significance ( $p=0.09)$ was detected. Vaginal penetration became possible in $97.87 \%$ of patients (46/47), while erectile function improved in almost half of them (42.55\%). 23 patients (48.93\%) needed to take PDE5i to enhance their nocturnal erections. Improvement in penile erogenous sensation was recorded in $6.38 \%(3 / 47)$ of patients.

Overall, 36 patients were satisfied with the outcome of

Figure 5.

Immediate post-operative period.

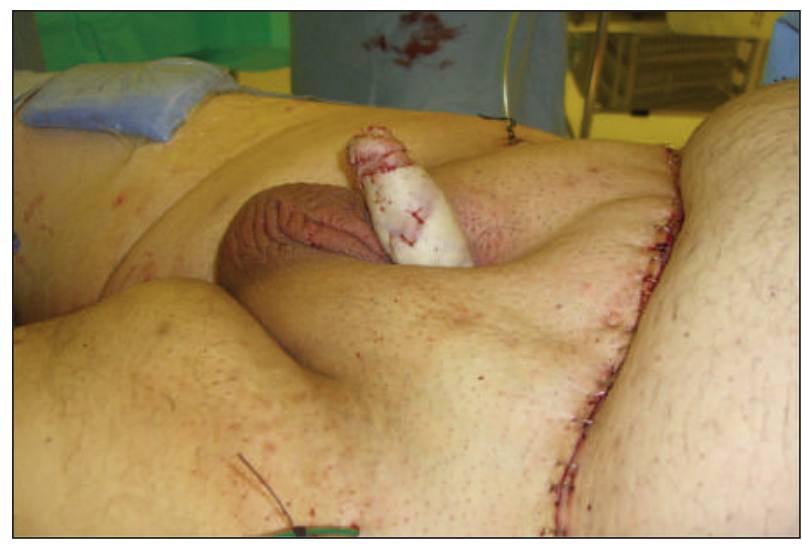

Figure 6.

Clinical presentation three months after surgery.

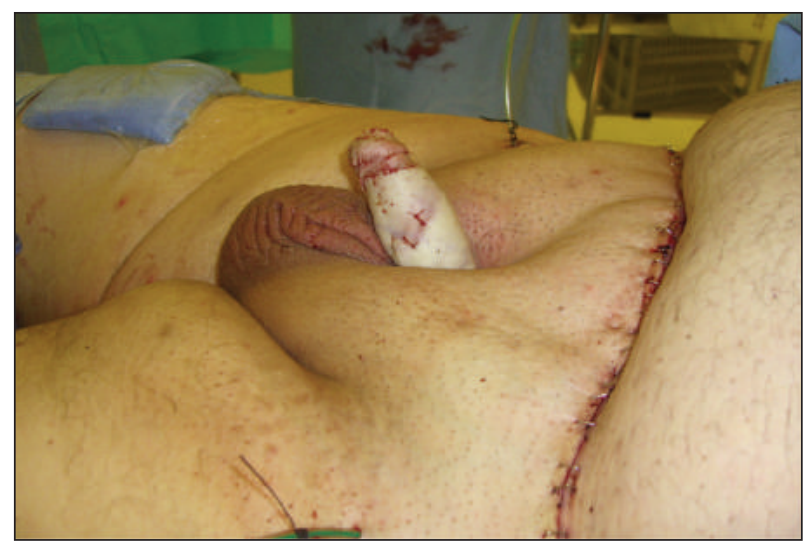

surgery (17 fully satisfied and 19 partially satisfied) while 8.51\% (4/47) declared to be dissatisfied, due to the small size of the discovered penis.

Table 2.

Postoperative complications and treatment $(n=47)$.

\begin{tabular}{|lcc|}
\hline Complication & Patient $(\mathbf{n})$ & Treatment \\
\hline Wound infection & 3 & Antibiotics \\
\hline Apronectomy site dehiscence & 2 & Surgical repair \\
\hline Myocardial infarction & 1 & Angioplasty \\
\hline Respiratory failure & 1 & Re-intubation \\
\hline
\end{tabular}

Table 3.

Functional outcomes after surgery $(n=47)$.

\begin{tabular}{|lcc|}
\hline Questionnaire & Value (SD) & P value \\
\hline Preoperative IIEF-5 & $15( \pm 12.72)$ & $\mathrm{p}=0.09$ \\
\hline Postoperative IIEF -5 & $18( \pm 12.02)$ & \\
\hline Preoperative HADS score & $18( \pm 8.48)$ & $\mathrm{p}=0.03$ \\
\hline \begin{tabular}{l} 
Postoperative HADS score \\
\hline Postoperative PGI-I score
\end{tabular} & $8( \pm 7.77)$ & \\
\hline $\begin{array}{l}\text { SD: Standard deviation; IIEF: International Index of Erectile Function; } \\
\text { HADS: Hospital Anxiety and Depression Scale; PGI-I: Patient Global Impression } \\
\text { of Improvement. }\end{array}$
\end{tabular}




\section{Discussion}

Buried penis is a non-specific term indicating both a pediatric and adult morbid condition characterized by the complete entrapment of phallus secondary to congenital or acquired etiologies. Acquired buried penis is becoming increasingly common, in concurrence with the prevalence of obesity (17). Nonetheless, no reliable data about the exact incidence of buried penis in adults are available.

In fact, this condition can significantly affect patients' quality of life as it compromises sexual and urinary function and renders urogenital hygiene almost impossible $(10,18)$

Furthermore, buried penis can be secondary to excessive pre-pubic adiposity or lymphoedematous tissue or to excessive penile shaft skin removal during circumcision (6). During micturition, urine from the buried urethral meatus drips over the scrotum and the thigh resulting in tissue maceration, infection, inflammation, scarring and chronic skin changes (19).

The main proposal for the management of adult buried penis is surgical correction. Several surgical techniques have been described, depending on the etiology of the buried penis.

When insufficient penile skin is available, either due to previous overzealous circumcision or because all skin is affected by LS and therefore needs to be removed at the time of surgery, adequate cover can be achieved with a STSG (20).

In case of excessive penoscrotal lymphoedema, all the lymphoedematous tissue has to be excised down to Buck's fascia on the penis and spermatic fascia on the testicles. Genital skin cover of the penis is achieved with preputial flaps, as they are never affected by lymphoedema, and STSG while scrotal reconstruction is achieved with craniodorsal flaps (21). If excessive suprapubic adiposity is the cause of the buried penis, the excessive adipose tissue has to be completely removed, either through an open suprapubic fat pad excision or liposuction. If excessive abdominal skin is present, the patient needs also to undergo an apronectomy to allow adequate exposure of the genitalia. Suspensory ligament division can be performed in combination with suprapubic fat pad excision in order to gain some extra penile length (17).

Donatucci et al. described a treatment algorithm ranging from release of scar contracture and primary closure (10). If insufficient release of the phallus through scar release occurs, then panniculectomy is justified.

Depending on the adequacy of skin or soft tissue for closure, the next step would be to use primary skin closure versus Z-plasty. If native skin is not available and/or of poor quality, then split thickness skin grafts or flaps may be necessary.

Skin flaps should only be used when an inadequate graft bed exists (14). As a common rule, in case of LS, genital skin should not be used for repair, as it can potentially develop LS in the future and STSG are the solution of choice (12).

Generally, thick STSG tend to heal with less contracture and dyschromia than their thin counterparts and therefore are ideal for penile shaft cover in patients who are keen to resume sexual activity. On the other hand, thin
STSG tend to have a better take and are therefore the solution of choice for coronal and glans reconstruction $(9,22)$.

The current series confirms the importance of surgically addressing buried penis in order to improve sexual and urinary function, which translates in a significant improvement in overall quality of life. In particular, according to literature, sexual penetration became possible in about $98 \%$ of cases and more than $90 \%$ of patients were satisfied with the outcome of surgery $(9,23)$. However, the main limitation of the current study was represented by the small number of the study cohort.

\section{Conclusions}

Surgical management of acquired adult buried penis is necessary as this condition can have a profound negative impact on quality of life.

In expert hands, excision of excessive adipose/lymphoedematous tissue and of genital skin affected by LS followed by reconstruction with STSG yields satisfactory functional results and allows restoration of sexual and urinary function in most patients.

\section{RefERENCES}

1. Keyes EL. Phimosis-paraphimosis-tumors of the penis. Appleton E Co, New York, NY, USA 1919.

2. Wollin M, Duffy PG, Malone PS, Ransley PG. Buried penis. A novel approach. Br J Urol. 1990; 65:97-100.

3. Crawford BS. Buried penis. Br J Plast Surg. 1977; 30:96-99.

4. Maizels M, Zaontz M, Donovan J, et al. Surgical correction of the buried penis: description of a classification system and a technique to correct the disorder. J Urol. 1986; 136:268-271.

5. Cromie WJ, Ritchey ML, Smith RC, Zagaja GP. Anatomical alignment for the correction of buried penis. J Urol. 1998; 160:14821484.

6. Mattsson B, Vollmer C, Schwab C, et al. Complications of a buried penis in an extremely obese patient. Andrologi.a 2012; 44(Suppl 1): 826-828.

7. Tausch TJ, Tachibana I, Siegel JA, et al Classification system for individualized treatment of adult buried penis syndrome. Plast Reconstr Surg. 2016; 138:703-711.

8. Frenkl TL, Agarwal S, Caldamone AA. Results of a simplified technique for buried penis repair. J Urol. 2004; 171:826-828.

9. Fuller TW, Theisen K, Rusilko P. Surgical management of adult acquired buried penis: escutcheonectomy, scrotectomy, and penile split-thickness skin graft. Urology. 2017; 108:237-238.

10. Donatucci CF, Ritter EF. Management of the buried penis in adults. J Urol. 1998; 159:420-424.

11. Rybak J, Larsen S, Yu M, Levine LA. Single center outcomes after reconstructive surgical correction of adult acquired buried penis: measurements of erectile function, depression, and quality of life. J Sex Med. 2014; 11:1086-1091.

12. Garaffa G, Shabbir M, Christopher N, et al. The surgical management of lichen sclerosus of the glans penis: our experience and review of the literature. J Sex Med. 2011; 8:1246-1253.

13. Yalcin I, Bump RC. Validation of two global impression ques- 
tionnaires for incontinence. Am J Obstet. Gynecol. 2003; 189:98101.

14. Rosen RC, Cappelleri JC, Gendrano N, $3^{\text {rd }}$. The International Index of Erectile Function (IIEF): a state-of-the-science review. Int J Impot Res 2002; 14:226-244.

15. D'Elia C, Cerruto MA, Cavicchioli FM, et al. Critical points in understanding the Italian version of the IIEF 5 questionnaire. Arch Ital Urol Androl. 2012; 84:197-201.

16. Zigmond AS, Snaith RP. The hospital anxiety and depression scale. Acta Psychiatr Scand. 1983; 67:361-370.

17. Adham MN, Teimourian B, Mosca P. Buried penis release in adults with suction lipectomy and abdominoplasty. Plast Reconstr Surg. 2000; 106:840-844.

18. Tang SH, Kamat D, Santucci RA. Modern management of adultacquired buried penis. Urology. 2008; 72:124-127.
19. Burns H, Gunn JS, Chowdhry S, et al. Comprehensive review and case study on the management of buried penis syndrome and related panniculectomy. Eplasty. 2018; 18:e5.

20. Triana Junco P, Dore M, Nunez Cerezo V, et al. Penile reconstruction with skin grafts and dermal matrices: indications and management. European J Pediatr Surg Rep. 2017; 5:e47-e50.

21. Garaffa G, Christopher N, Ralph DJ. The management of genital lymphoedema. BJU Int. 2008; 102:480-484.

22. White N, Hettiaratchy S, Papini RP. The choice of split-thickness skin graft donor site: patients' and surgeons' preferences. Plast Reconstr Surg. 2003; 112:933-934.

23. Hughes DB, Perez E, Garcia RM, et al. Sexual and overall quality of life improvements after surgical correction of "buried penis". Ann Plast Surg. 2016; 76:532-535.

\section{Correspondence}

Andrea Cocci, MD, Ph.D (Corresponding Author)

cocci.andrea@gmail.com

Gianmartin Cito, MD

Fabrizio Di Maida, MD

Careggi Hospital, Department of Urology, University of Florence

Largo Brambilla 3 - 50139 Florence (Italy)

Marco Falcone, MD

Molinette Hospital, Department of Urology, University of Turin, Turin (Italy)

Marco Capece, MD

Department of Urology, University of Naples, Naples (Italy)

Girolamo Morelli, MD

Department of Urology, University of Pisa, Pisa (Italy)

Nim Christopher, MD

David Ralph, MD

Giulio Garaffa, MD

The Institute of Urology, UCLH, and International Andrology, London (UK) 